\title{
Correction to: A new semi-automated workflow for chemical data retrieval and quality checking for modeling applications
}

Domenico Gadaleta ${ }^{*}$, Anna Lombardo ${ }^{\dagger}$, Cosimo Toma and Emilio Benfenati

\section{Correction to: J Cheminform (2018) 10:60} https://doi.org/10.1186/s13321-018-0315-6

It was highlighted that the original article [1] contained an error in the Funding section. This Correction article states the correct and incorrect versions of the Funding section.

\section{Correct Funding}

This work has received funding from the European Union's Horizon 2020 research and innovation programme under Grant Agreement No. 681002 (EU-ToxRisk) and from the LIFE Project LIFE15 ENV/ES/000416 (LIFE-COMBASE).

\section{Incorrect Funding}

This study was funded by EU-ToxRisk (Project Reference: 681002) and LIFE-COMBASE (LIFE15 ENV/ES/000416).

\section{Publisher's Note}

Springer Nature remains neutral with regard to jurisdictional claims in published maps and institutional affiliations

Received: 17 April 2019 Accepted: 17 April 2019

Published online: 25 April 2019

\section{Reference}

1. Gadaleta et al (2018) A new semi-automated workflow for chemical data retrieval and quality checking for modeling applications. J Cheminform 10:60. https://doi.org/10.1186/s13321-018-0315-6

\footnotetext{
*Correspondence: domenico.gadaleta@marionegri.it

${ }^{\dagger}$ Domenico Gadaleta and Anna Lombardo have contributed equally to this work

Laboratory of Environmental Chemistry and Toxicology, Department of Environmental Health Sciences, Istituto di Ricerche Farmacologiche Mario Negri IRCCS, Via la Masa 19, 20156 Milan, Italy
} 